IZA DP No. 6372

Segregation, Choice Based Letting and Social Housing: How Housing Policy Can Affect the Segregation Process

Maarten van Ham

David Manley

February 2012 


\title{
Segregation, Choice Based Letting and Social Housing: How Housing Policy Can Affect the Segregation Process
}

\author{
Maarten van Ham \\ Delft University of Technology \\ and IZA
}

David Manley

University of Bristol

\author{
Discussion Paper No. 6372 \\ February 2012
}

\author{
IZA \\ P.O. Box 7240 \\ 53072 Bonn \\ Germany \\ Phone: +49-228-3894-0 \\ Fax: +49-228-3894-180 \\ E-mail: iza@iza.org
}

\begin{abstract}
Any opinions expressed here are those of the author(s) and not those of IZA. Research published in this series may include views on policy, but the institute itself takes no institutional policy positions.

The Institute for the Study of Labor (IZA) in Bonn is a local and virtual international research center and a place of communication between science, politics and business. IZA is an independent nonprofit organization supported by Deutsche Post Foundation. The center is associated with the University of Bonn and offers a stimulating research environment through its international network, workshops and conferences, data service, project support, research visits and doctoral program. IZA engages in (i) original and internationally competitive research in all fields of labor economics, (ii) development of policy concepts, and (iii) dissemination of research results and concepts to the interested public.
\end{abstract}

IZA Discussion Papers often represent preliminary work and are circulated to encourage discussion. Citation of such a paper should account for its provisional character. A revised version may be available directly from the author. 


\section{ABSTRACT \\ Segregation, Choice Based Letting and Social Housing: How Housing Policy Can Affect the Segregation Process}

In this chapter we investigate the process of ethnic minority segregation in English social housing. Successive governments have expressed a commitment to the contradictory aims of providing greater choice - through the introduction of choice based letting - for households accessing an increasingly marginalised social housing sector whilst also expressing a determination to create more mixed communities and neighbourhoods. We consider the concept of choice in the context of a heavily residualised social housing sector, arguing that, for social housing tenants at least, the concept of real choice is a misnomer. We draw on research that has utilised unique administrative data and analysed the moves of all entrants into and movers within the social renting sector over a ten year period in England. The conclusion is that the introduction of choice based letting has influenced the residential outcomes of ethnic minorities and resulted in highly structured neighbourhood sorting that has segregated minority populations into the least desirable neighbourhoods of English cities.

JEL Classification: R21, R23

Keywords: $\quad$ segregation, choice based letting, social housing, housing policy, UK

Corresponding author:

Maarten van Ham

OTB Research Institute for the Built Environment

Delft University of Technology

P.O. Box 5030

2600 GA Delft

The Netherlands

E-mail:m.vanham@tudelft.nl

\footnotetext{
* The paper will be published as a book chapter in: Social-Spatial Segregation: Concepts, Processes and Outcomes. Edited by Christopher D Lloyd, Ian Shuttleworth and David Wong. The Policy Press.
} 


\section{Introduction}

Many of the chapters in this volume report on the ways in which segregation can be measured (see for example Johnston, this volume), or the degree to which specific populations are segregated in the residential or even school context (see for example Harris, this volume). At the heart of these chapters is a discussion about segregation indices either as a means through which the state of segregation can be measured and reported or as a problematic indicator that requires careful consideration and deployment. This chapter takes a different approach by investigating neighbourhood sorting. The study of segregation is, at one level, the study of variance in neighbourhood characteristics. That is to say the amount by which the population in one place varies compared to the expected mean level of variation. Whilst it is important to identify where high and low levels of variation occur, of more importance is the understanding of how the variation occurs in the first place. As a consequence, we explicitly explore the dynamic nature of the neighbourhood and the flows of households into neighbourhoods of different types of neighbourhoods. This chapter reports research investigating the effect of choice based letting (CBL) on how prospective social housing tenants sort into dwellings and neighbourhoods and how household choice influences the composition of a neighbourhood. CBL was introduced in the early 2000s by the then labour government in England to enable social housing tenants to select their property moving away from a landlord led allocation system through which social housing had previously been let. CBL was also charged with promoting letting in neighbourhoods that were traditionally hard to allocate either through reputation or perceived undesirability. A focus on these sorting processes within the social housing sector is largely missing in the current segregation literature.

This chapter draws on three literatures. The fist literature is concerned with the issue of household residential choice and demonstrates that when households are able to exercise choice over their residential location they will, all other being equal, choose to live in residential environments that are comprised of other households with similar characteristics (see Schelling, 1969; Clark, 1991; 1996; Peach, 1998). Of course, choice itself is a luxury good, one which some households are better able to execute than others. Real choice can be thought of as having the ability to choose a preferred outcome from a set of distinct options. However, even in the owner occupier housing market, real choice rarely exists. A key determinant of choice in the residential housing market is finance - the ability to pay for access to better neighbourhoods and dwellings is crucial to being able to express one's own choice. Thus, households with limited access to financial resources will be less well placed to exercise choice.

The second literature on which this chapter draws is concerned with the changing role of the social housing sector in the United Kingdom. Successive governments in the UK have sought to reduce the size of the social housing sector. Through policies such a the right to buy, reduction of new social landlord building grants, and through the introduction of mixed tenure communities replacing large social housing estates, the proportion of the population living in the social housing sector has fallen from $32 \%$ in 1971 to $18 \%$ in 2009 . Clearly, against a backdrop of a falling tenure mode, the notion of choice has a very specific meaning, and we enter into a discussion about this below. The third literature on which this chapter is based is concerned with segregation in neighbourhoods. We briefly highlight the way in which segregation has been portrayed in the academic literature and the concern of the British government to the assumed negative effects of concentrations of ethnic minority groups in specific spaces within many of the towns and cities. We related this concern to the policy context as a means to understand the policy context within which CBL was launched. This chapter proceeds as follows. First we identify key themes from the literature outline above and set out how housing and neighbourhood choice can lead to segregated outcomes. 
Following on from this, we discuss the changing nature of social housing in the UK over the last 30 years. These discussions are then brought together when we outline the policy environment that led to the marketization of social housing and the introduction of CBL. Second, we discuss two case studies on the effects of CBL on neighbourhood sorting and segregation... The third and final section presents the conclusions.

\section{Background}

\section{Residential and Tenure Segregation in the UK}

The spatial concentration of ethnic minorities in specific neighbourhoods is of great concern to the British Government, and was highlighted as one of the causes of the 2001 Riots in several towns and cities in Northern England (Independent Review Team, 2001; Commission for Racial Equality, 1990; 2004). The severity of ethnic and socio-economic separation within England has been debated at length, and terminology such as segregation and ghettoisation has become severely loaded. Using 1991 Census data for the United Kingdom, Champion (1996) reported that in England ethnic minorities are spatially dispersed and that areas with the highest concentrations of ethnic minorities do not match the image of racialised 'ghettos' as known in the USA (see also Peach, 1996; Johnston et al., 2002). In a more recent analysis using the 2001 Census, the national trend of dispersion of ethnic minorities, albeit with pockets of ethnic concentrations, was confirmed by Johnston (2006, p.988). Using both 1991 and 2001 Census data, Dorling and Rees (2003) suggested that there was evidence at the local authority level of increasing segregation between the white majority and ethnic minorities. Using proxy measures, such as access to bathrooms and central heating as indicators of socio-economic status, Dorling and Rees (2003) also point to growing segregation between housing tenures: " $[\mathrm{t}] \mathrm{o}$ be growing up in a council house now marks a household out geographically far more than it did a decade ago" (p.1301). Concerns have also been expressed about the concentration of ethnic minorities in social housing which suggests that ethnic minorities are less able than others to satisfy their housing needs in the market (Cabinet Office, 2003; Home Office 2001). There is, of course, interaction between socioeconomic and ethnic segregation. The proportion of ethnic minorities in the overall population in England was around 9 per cent at the time of the 2001 Census. Ethnic minorities are generally concentrated in large urban areas, and are over represented in social housing. On average, 17 per cent of the white population in England lives in social housing and 27 per cent of the ethnic minority population lives in social housing (SEH, 2007).

The selective mobility of residents into and out of neighbourhoods has the potential to create and reinforce patterns of deprivation and segregation (Bailey \& Livingstone, 2008; Van Ham \& Feijten, 2008; Feijten \& Van Ham, 2009; Van Ham \& Clark, 2009). Individual preferences related to the ethnic composition of the neighbourhood population, and the consequent moving behaviour of these individuals, can cumulate in aggregate to highly segregated neighbourhoods (Schelling, 1969, 1971; see also Clark, 1992; Emerson et al., 2001; Ihlanfeldt and Scafidi, 2002; Ionnides and Zabel, 2003). Alternatively, the 'racial proxy hypothesis' argues that members of the majority population leave ethnic concentration neighbourhoods not because they have an aversion to living near minority group members per se, but because these neighbourhoods are often deprived (Taub et al., 1984; Clark, 1992; Harris, 1999; Crowder, 2000). This is partly because some ethnic minority groups are more likely to be unemployed and have lower incomes than the majority population, and partly because ethnic minorities often end up in low income, deprived and unstable neighbourhoods as a result of limited choice on the housing market.

Simpson (2004) has highlighted that to fully understand apparent neighbourhood segregation it is necessary to move beyond issues of selective migration. Using demographic 
data for Bradford, Simpson (2004) reported that significant changes in the relative distribution of the South Asian community, relative to rest of the population, was caused by natural population growth. Bradford was one of the cities in the North of England that experienced riots during the summer of 2001, and it is notable that Simpson's conclusion on the causes of segregation was at odds with the government report which focussed on selfsegregation of ethnic minorities through their residential choices (Independent Review Team, 2001). The same report does not acknowledge that 'self-segregation' is often rooted in poverty and deprivation, and not necessarily the result of real choice (Hickman and Robinson, 2006; Robinson, 2005; van Ham and Manley, 2009; Manley and van Ham, 2011).

\section{Social Housing Allocation in the UK}

Housing allocation practices from as far back as the 1950s have been linked to current patterns of ethnic segregation. It was repeatedly shown that housing officers intentionally and unintentionally promoted segregated outcomes by discriminating applicants based on ethnicity and socio-economic background and allocated households to dwellings and neighbourhoods based on whether they 'deserved' a dwelling, or were 'suitable' for a neighbourhood (Simpson, 1981; Henderson \& Karn, 1984; Clapham \& Kintrea, 1984; Malpass \& Murie, 1994; Peach, 1996; Somerville, 2001; Sarre et al., 1989). Prior to the 1970s social housing in the UK was allocated by housing officers who were able to exercise a high degree of discretion in judging whether or not a family 'deserved' to live in a property. This process was not very transparent and has been acknowledged as a means through which ethnic minority segregation was reproduced overtime. From the 1970s onwards, social housing in England was allocated following a needs-based system. However, the needs based system did not completely democratise the system. In many cases, front-line housing officers and local councillors still maintained some discretionary powers (Henderson and Karn 1984; Fitzpatrick and Stephens 1999). Needs-based systems were designed to introduce objectivity in the housing allocation process. Categories of reasonable preference were created and enabled a mechanism through which groups competing for the same properties could be prioritised. Even after needs-based systems were introduced, research still demonstrated that the allocation processes through which tenants gain access to social housing have tended to concentrate the most disadvantaged individuals in the least attractive areas (see for example, Henderson and Karn 1984; Clapham and Kintrea 1986). This finding this important, as it is through the house and therefore by extension the neighbourhood in which individual's centre their lives. In short, where you live has an effect on your ability access to many public and private services, employment and social opportunities. As Pawson and Kintrea noted, "housing processes have the potential to be a force for social exclusion by creating and maintaining social and spatial divisions and thereby providing barriers to jobs, education and other services" (2002, p.646). There are a number of competing issues to be considered here. Firstly, the allocation systems through which prospective tenants must navigate are set up, in many cases, not to assist them to achieve the best housing outcome based on their own characteristics and desires, but to assist landlords to manage their housing stock and the demand for properties with varying levels of attractiveness. Research by Fitzpatrick and Pawson (2006), and Mullins and Pawson (2005) has shown that the traditional routes into social housing restrict prospective tenants in terms of the type of housing, including the location, available to them. Further restrictions on households exercising choice are apparent in the allocation system. When offered properties, households could refuse an offer made, but doing so usually led to penalties, including temporary suspension from the housing waiting list (Pawson \& Watkins, 2007) or even exclusion through one-offer-only policies (Pawson \& Kintrea, 2002). Of all the factors that can influence the outcome of a move into or within the social housing sector the ability to wait is a key driver (Mullins and Pawson 2005; Pawson 
and Kintrea 2002; Fitzpatrick and Stephens 1999). Fitzpatrick and Pawson noted that "the importance of the 'ability to wait' in driving spatial polarisation is germane to the potential impact of the 'choice' agenda" (2006 p.172). This is especially true as in cases where households with similar needs bid on the same property, waiting time is often used as a means to allocate the dwelling to the household with the longest waiting time. All other things being equal, turnover rates are greater in less popular housing and in less popular neighbourhoods. As a result, more popular properties and more popular neighbourhood tend to become available less often. Households with more urgent housing needs, and with less time to wait are less likely to be able to invest time in the search for a new property in a popular neighbourhood. This is particularly an issue for new entrants into the social housing sector, accessing housing because of eviction or repossession, or other groups requiring accommodation quickly such as those fleeing domestic violence.

In $2001 \mathrm{CBL}$ was introduced to empower people in social housing to make decisions over how and where they live (DETR, 2000b, Brown \& Yates, 2005; Brown \& King, 2005). The model for CBL came from the 'advert' or 'supply' model developed in the late 1980s in the city of Delft in the Netherlands (Kullberg, 1997; 2002). The system was designed to "open up the letting of social housing" and operates by enabling eligible households to bid on a range of properties (Pawson et al., 2006, p.5). In instances where more than one household applied to bid on the same property, eligibility is determined using 'currency' to rank bidders. Currency could include points based on household characteristics (the presence of children) and waiting time or housing need bands (Marsh et al., 2004). Within the CBL framework, social landlords still have the legal obligation to operate a needs-based allocation system. By introducing a quasi-market system into social housing allocation it was hoped that demand would be stimulated in harder to let areas (Marsh, 2004), and that households would be encouraged to become stakeholders in their neighbourhoods of choice.

\section{Neighbourhood and housing 'choice'}

The concept of 'choice' in relation to housing and neighbourhoods is often used in policy documents and academic literature and frequently has positive connotations. However, the concept of 'choice' is highly misleading in housing studies: it is unlikely that a household behaving rationally would choose to live in poor quality housing or a dangerous neighbourhood (van Ham, 2012). Instead, housing and neighbourhood outcomes are the result of an interplay between preferences, opportunities and restrictions on the one hand and housing stock availability and allocation mechanisms on the other. Real choice is assumed to exist when individuals are able to choose a preferred option from a set of distinct alternatives (Elster, 1999; Brown and King, 2005). Within the social housing sector it is hardly possible to speak of real choice as often there are no real distinct alternatives. Examining housing choice is complicated by the fact that housing is a composite good. Housing can be thought of in many terms, including size, number of bedrooms, style, quality and relative location. However, none of these aspects can be purchased individually and dwellings come as a bundle of goods. This bundle also includes the neighbourhood and access to jobs as well as to private and public facilities (van Ham, 2012).

There are substantial differences in the degree to which choice can be exercised between tenures. For instance, those searching in the owner occupied market are likely to be able to express a greater degree of choice than those households depending on the social housing sector. Brown and King (2005) describe social housing as a gift from the bureaucracy that controls it, as even under CBL the state sets the rules governing which households can bid on which properties. 


\section{Housing choice and segregation}

There is a long history of work investigating the role of neighbourhood choice as a driver for neighbourhood segregation. The work of Schelling $(1969 ; 1971)$ is often regarded as the starting point of this literature. He argued that many households have a preference for living in neighbourhoods with households of similar (ethnic) background and that these preferences can lead to highly segregated neighbourhoods. Using empirical data from the United States, Clark (1991) demonstrated that the Schelling hypothesis was broadly correct, and that even small differences in preferences between ethnic groups with regard to the ethnic composition of neighbourhoods can lead to highly segregated communities (see also Fossett, 2006). Similarly, evidence from both Europe and the United States indicates that ethnic segregation is primarily driven by own-group preferences held by the majority population. In addition, the majority population tends to have the greatest level of resources and, therefore, the ability to put these preferences into action. For example, Clark (1991) reports that while whites preferred the ethnic mix in their neighbourhood to be at least $80 \%$ white, blacks seemed to prefer a 50/50 mix. Work from Sweden by Bråmå (2006) demonstrated that the most immigrant-dense neighbourhoods are truly multicultural, making the notion of voluntary ethnic minority clustering unlikely. Ethnic mix preferences (or rather preferences for relative homogeneity) by the majority population are apparent at the aggregate level through patterns of white avoidance of ethnic minority neighbourhoods. However, whilst Schelling and others have emphasised household preference as means to understand residential sorting patterns, especially with respect to ethnic minority concentration in neighbourhoods, other authors have highlighted the importance of discrimination within housing markets, either through realtors not showing properties to families from ethnic minority backgrounds or finance companies making credit harder to obtain (see for instance Galster, 1976).

Studies from various countries have found that ethnic minorities are more likely than natives to move to ethnic concentration neighbourhoods. It has been hypothesised that these moves to ethnic concentration neighbourhoods are (partly) motivated by the desire to live in areas with others who have common life experiences and by the availability of ethnic-specific services (see Bowes et al, 1997). Other studies have emphasised the impact of socioeconomic differences between ethnic and non-ethnic groups (e.g. Clark and Ledwith, 2006; South and Crowder, 1997; 1998). In Sweden ethnic minorities are overrepresented among the lower income groups, and as a result they concentrate in low-cost neighbourhoods. Similar evidence has been presented for from the Netherlands (see Bolt et al 2008). Bråmå and Andersson $(2005$; 2010) have shown that recent immigrants in Sweden initially move to areas with high densities of immigrants. When their income improves they are more likely to leave these neighbourhoods and move to less ethnically concentrated neighbourhoods. Discrimination has also been shown to influence neighbourhood ethnic sorting [e.g. Turner et al (2002) for the United States], although the extent to which this is valid for Sweden is unclear (Bråmå, 2007).

\section{Choice Based Lettings and segregation}

One of the possible negative side effects of a system that promotes household choice, such as $\mathrm{CBL}$, is that it could lead to increased levels of segregation, or at the very least sustain current levels of segregation, as households are able to influence where they will live. As the debate above highlighted, once households are empowered to express their preferences then we would expect that they would seek to live in neighbourhoods that had a majority of other residents similar to themselves (as suggested by Schelling, 1971). However, it has also been argued that a lack of real choice in CBL, and not self-segregation, might be a cause of social and ethnic segregation in neighbourhoods (Pawson \& Watkins, 2007; see also van Ham \& Manley, 2009; Manley and van Ham, 2011). Having real choice means being able to select a 
preferred option from distinctive alternatives, and the process of CBL presumes that households will act rationally. In social housing, a safety net for those without options, distinctive alternatives might not be available. Research by Marsh and colleagues (2004) showed that tenants, who accessed social housing using CBL, identified a lack of choice as a real problem. Tenants stated that they frequently ended up bidding on properties and neighbourhoods they deemed to be of sub-standard quality. An essential prerequisite for real choice is information (knowledge) about alternatives (see Elster, 1999 as in Brown \& King, 2005). Some social housing applicants using CBL will have more and better information than others, either as a result of English language skills (Pawson et al., 2006), skills in using the CBL system, time to assess alternatives, or greater knowledge about the local housing market and neighbourhoods in their choice set. Ultimately, this will bias the allocation system in their favour (Brown \& King, 2005). Research in the Netherlands showed that applicants with low incomes and those from ethnic minority groups (often overlapping groups) were more likely to lack understanding of the CBL system and therefore fared less well in terms of housing outcomes (Kullberg, 2002).

CBL might also lead to segregation because those with urgent housing needs, but without priority status, use their choice to bid on the easiest-to-get dwellings which increases the likelihood to be accommodated in a less desirable area (van Ham \& Manley, 2009). As noted above, the ability to wait is crucial in exercising choice. As a result of the above, concerns have been expressed that CBL might be detrimental to the interests of already disadvantaged groups (Pawson \& Watkins, 2007). Ethnic minorities may end up in ethnic concentration neighbourhoods, and especially deprived ethnic concentration neighbourhoods, not as a result of choice, but as a result of a lack of choice (van Ham \& Manley, 2009).

Prior to the work of Manley and van Ham (2011) and van Ham and Manley (2009), work assessing the impact of CBL on segregation has largely focussed on changes in the level of segregation in the neighbourhoods affected. Work for the Department of Communities and Local Government (Pawson et al., 2006), and extended in Pawson and Watkins (2007), used a number of case studies from social housing estates and concluded that "there is no evidence that [CBL] has resulted in more ethnically polarized patterns of letting than those arising from previous lettings systems where decisions on which properties to offer to which applications were largely in the hands or landlord staff" (Pawson et al., 2006, p.14; see also Pawson \& Watkins, 2007). In terms of ethnic mix in communities Pawson and colleagues found that " $[\mathrm{m}]$ any applicants preferred ethnically mixed areas, rather than areas where one ethnicity predominated, which suggests that diffusion is more likely than segregation under CBL" (2006, p.183). However, measuring a change in neighbourhood segregation requires information on the outflow of households from neighbourhoods as well as the inflows. If the outflow of a neighbourhood was comprised solely of one ethnic group (such as in extreme cases of 'white flight') then the ultimate degree of segregation would be very different a neighbourhood in which an equal share of ethnic and non-ethnic minority individuals were leaving. In their study, Pawson and colleagues (2006) only collected information about the households entering neighbourhoods (inflow) and not those households leaving the neighbourhoods. As such, they are incorrect to conclude that under CBL segregation is decreasing. The CBL process also requires that prospective tenants are willing and able to invest time into understanding the housing system that they are using and that they will make rational, normative decisions in their housing and neighbourhood choices.

\section{An English Case Study}

The empirical evidence presented in this chapter builds on two papers (van Ham and Manley, 2009; Manley and van Ham, 2011). Both of these papers use unique data from lettings made to tenants in social housing in England during the 2000s collected by the Department for 
Communities and Local Government (DCLG). Each time a socially rented dwelling was let (either from a Housing Association or a Local Authority) a record was created. This record was stored as part of the CORE database (COntinuous REcording) and contained information on both the property and household. Legislation in England meant that all social landlords with more than 250 units or bed spaces were legally required to complete the CORE logs fully. In practice many landlords smaller than the regulation size also participated. Because of the comprehensive level of coverage, the CORE dataset can be treated as a Census of all social housing lettings made in England during any given year, and can be regarded as flow data depicting the flows of households into social housing. It is also possible to include detailed information about local neighbourhoods because CORE data includes low level geocoding for each letting. This information includes neighbourhood characteristics such as the level of neighbourhood deprivation, or the proportion of the neighbourhood belonging to ethnic minority groups.

Van Ham and Manley (2009) investigated the probability that ethnic minority households are more likely to enter neighbourhoods with a high concentration of other members of ethnic minority groups. Neighbourhoods were defined using the administrative units Super Output Areas (SOAs). SOAs contain on average 1,500 people and were designed to represent 'neighbourhoods' for the publication of low level statistics in the United Kingdom. Using the SOAs, neighbourhoods were classified using the proportion of ethnic minority residents, derived from the 2001 Population Census for England. The groups were: 0 to $2.5 \% ; 2.5$ to $5 \% ; 5$ to $10 \% ; 10$ to $20 \% ; 20$ to $40 \%$ and 40 to $100 \%$. The models were used to predict if an ethnic minority household was more likely to enter a neighbourhood with a high concentration of ethnic minorities than white households and whether or not that likelihood was increased when properties were let under CBL. The results of the analysis show that for ethnic minority households the most likely neighbourhood outcome is to enter in a neighbourhood with between $20-40 \%$ of the population also belonging to an ethnic minority. This outcome is more likely for ethnic minority residents using CBL than those using one of the other allocation systems. In all cases, ethnic minority households are more likely than white households to enter neighbourhoods with a high proportion of households also from ethnic minorities especially when using CBL. In comparison, the white population are most likely to enter neighbourhoods with $0-10 \%$ and $10-20 \%$ concentration of ethnic minorities, even when they move from neighbourhoods with higher concentrations of ethnic minorities. Unlike the ethnic minority group, there are no differences in the probabilities between white households who use CBL and those using the other access routes.

Manley and van Ham (2011) combine multiple years of CORE data to conduct two analyses. In the first analysis areas were matched where $100 \%$ of the lettings were made using CBL in 2008/2009 with the same areas in 1999/2000 (before CBL was introduced). This allowed the geography of the areas to be held constant and a direct pre-CBL to postCBL comparison made. The second analysis used all the letting data from 2008/9 and analysed the flows of individuals using either CBL or non-CBL allocation routes in that year. The dependent variable of the models was also adjusted to combine measures of ethnic concentration and neighbourhood deprivation. Neighbourhood deprivation was measured using the Index of Multiple Deprivation (IMD) for England (ODPM, 2007) and the 2001 Census for the percentage of ethnic minorities in neighbourhoods. The first year for which the IMD data is available at the SOA level is 2004, As a result, the IMD 2004 was linked to the 1999/2000 data and the IMD 2007 to the 2008/9 data. Although the dates of the IMDs are not identical to the dates of the lettings, it is valid to use deprivation information from different time periods as deprivation is largely static over time (see Meen et al., 2007). Innovatively, instead of directly using the national absolute measures of neighbourhood deprivation and ethnicity we created bespoke relative measures for local housing markets. 
Given that most households search locally, not nationally, for housing, we chose to create variables reflecting the relative position of a neighbourhood in the local housing market. Travel to Work Areas (TTWA) were used to represent local housing markets. These areas are defined so that $75 \%$ of those living in the area also work in the area vice versa, meaning that they capture local housing search areas effectively (see Coombes \& Raybould, 2004).

The outcome variable for the analysis was constructing using a combination of deprivation from the Index of Multiple Deprivation and the proportion of the population identified as belong to an ethnic minority. In each case the 20 per cent most deprived Super Output Areas in each Travel to Work Area we identified. This gave a bespoke relative measure of neighbourhood deprivation and ethnicity for each housing market. Neighbourhoods were classified into four groups for the dependent variable: (1) non-deprived and White concentration neighbourhoods; (2) deprived but not ethnic concentration neighbourhoods; (3) non-deprived but ethnic concentration neighbourhoods, and; (4) deprived and ethnic concentration neighbourhoods. These four categories are based on research which shows that many people see deprived neighbourhoods and ethnic concentration neighbourhoods as less desirable (Harris, 1999; Bolt et al., 2008). Manley and van Ham argued that these four types of neighbourhoods can act as a proxy for neighbourhood desirability within local housing markets, where the first type of neighbourhood is more desirable than the other three types (although there is no particular order between types two, three or four). With a multinomial response variable (with 4 outcomes) and clear hierarchical structures within the data (local neighbourhoods as SOAs within TTWA housing markets) the most appropriate model was a multinomial, multilevel model (see Manley and van Ham 2011 for details).

The results of the analysis are presented in table 1. For both the comparative 1999/2000 with 2008/2009 approach and the cross sectional 2008/2009 approach ethnic minorities are consistently more likely to enter neighbourhoods with concentrations of other ethnic minorities and neighbourhoods that have a high level of deprivation. The table shows that, compared to the white population before the introduction of CBL (see the top half of the table) ethnic minorities are 1.29 times more likely to end up in deprived neighbourhoods, 2.63 times more likely to end up in ethnic concentration neighbourhoods and 3.08 times more likely to end up in deprived ethnic concentration neighbourhoods. After CBL, the sorting effects are stronger, with members of ethnic minorities 4.60 more likely to enter the same type of neighbourhood than the white population. It is also notable that the white households using CBL are actually less likely than white households renting prior to the introduction of CBL to enter deprived and ethnic minority concentration neighbourhoods. Thus, there were strong sorting mechanisms present in the allocation of social housing prior to the introduction of CBL. After CBL had been introduced, this sorting pattern became more pronounced, with ethnic minorities 4.6 times more likely to enter deprived and ethnically concentrated neighbourhoods compared with white households prior to CBL. It is notable that white households are less likely (0.9 times) to enter these neighbourhoods after the introduction of CBL compared with the same households before CBL. The bottom half of the table reports the findings of the analysis post CBL and a similar trend can be seen. Ethnic minority households are more likely that White households to enter areas with higher concentrations of ethnic minorities as well as areas with higher level of deprivation. The ethnic minority groups are 1.5 times more likely than the White group to enter a deprived neighbourhood, 1.2 times more likely to enter an ethnic concentration neighbourhood and 1.6 times more likely to enter a neighbourhood with high levels of deprivation and ethnic concentration. The results also show that ethnic minorities using CBL are far more likely than others (including ethnic minorities using the other allocation mechanisms) to rent a dwelling in deprived neighbourhoods, ethnic concentration neighbourhoods and especially deprived ethnic 
concentration neighbourhoods. Compared to those renting without CBL, ethnic minority households are now 2.2 times more likely than the White group to enter a deprived neighbourhood, 1.7 times more likely to enter an ethnic concentration neighbourhood and 2.7 times more likely to enter a neighbourhood with high levels of deprivation and ethnic concentration than the White population. This demonstrates that there is a clear sorting of the population through social housing letting. These results suggest that ethnic segregation through CBL is not just the result of choice as ethnic minorities are also more likely to end up in the more deprived neighbourhoods, even when these are not ethnic concentration neighbourhoods. We discuss this finding further in the final section of this chapter.

Table 1: Total effects of ethnicity and choice-based letting (odds ratios),

\begin{tabular}{l|c|c|c}
\hline \multicolumn{1}{c|}{ Neighbourhood Type } & Deprived & $\begin{array}{c}\text { Ethnic } \\
\text { Concentration }\end{array}$ & $\begin{array}{c}\text { Deprived \& Ethnic } \\
\text { Concentration }\end{array}$ \\
\hline \multicolumn{3}{l}{ Total effects using data from 1999/2000 and 2008/9 for HA lettings in urban areas } \\
\hline White before CBL & 1.00 & 1.00 & 1.00 \\
Ethnic before CBL & 1.29 & 2.63 & 3.08 \\
White after CBL & 1.48 & 1.24 & 0.90 \\
Ethnic after CBL & 2.10 & 4.05 & 4.60 \\
\hline \multicolumn{2}{l|}{ Total effects using data from 2008/9 for HA and LA lettings } \\
\hline White, not using CBL & 1.00 & 1.00 & 1.00 \\
Ethnic minority, not using CBL & 1.59 & 1.24 & 1.60 \\
White, using CBL & 1.19 & 1.07 & 1.13 \\
Ethnic minority, using CBL & 2.20 & 1.70 & 2.68 \\
\hline
\end{tabular}

Source: Author's own calculations using CORE and LACORE lettings data 1999/2000 \& $2008 / 9$

\section{Discussion and Conclusions}

This chapter has suggested that in order to understand residential segregation a number of literatures need to be brought together and that segregation analysis should focus on flows of households into neighbourhoods rather than on static indices. This example has been illustrated by examining the flows of social housing tenants and has demonstrated the implications that these flows have for the degree to which socio-economic and more specifically ethnic segregation can occur. By combining literatures on housing choice and neighbourhood sorting we highlighted the likely outcomes of government policies introduce choice into the social housing market. Given the spatial fixity of housing - once located in a neighbourhood a property cannot be moved, and changes to the characteristics of the neighbourhood tend to occur slowly over time - understanding how households sort into dwellings and neighbourhoods is crucial for understanding how residential segregation develops and is maintained over time. The vast majority of the residential segregation literature tends to assume that households are able to exercise choice and do not face substantial spatial constraints. When turning the discussion to the social housing sector, the third of the literatures, the debate must be refocused and the limited number of options recognised. When discussing the social housing sector choice becomes a much more restricted good and the potential for prospective tenants to use choice to subvert the social housing allocation system and in a non-rational manner increases. No longer does choice become about exercising a preferred option among a range of distinct alternatives but it becomes more about satisfying other, more immediate housing needs. 
In contrast to the CLG sponsored research (see CLG, 2006; Pawson and Watkins, 2007) which was based on a limited number of early CBL case studies we argue that the process of CBL is contributing to, at best, a stabilising of segregation levels across social housing communities or at worst an increase in segregation. Based on the two analyses presented above we draw three conclusions about the structure of social housing allocations and the potential of that sector to create segregated communities. The first conclusion is that among those who do not use CBL, ethnic minority households are far more likely than White households to enter deprived and especially ethnic-concentration neighbourhoods. In other words, there are differences in households and letting structures differences that lead to differential outcomes for ethnic and White tenants even when choice is not exercised through choice based lettings. The second conclusion is that those who rent their dwelling using CBL (both non-minority and ethnic minority households) are more likely to end up in a deprived neighbourhood (and to a lesser extent in an ethnic-concentration neighbourhood) than those who get their dwelling using the older allocation systems. This is borne out by the analyses presented in both van Ham and Manley (2009) and Manley and van Ham (2011) using multiple years worth of data and multiple analytical methods. It is likely that this is partly a function of the neighbourhoods in which CBL has been rolled out in the initial phases of the policy development. CBL was used primarily as a means to stimulate demand in areas that had traditionally been harder for landlords to let. As such it was less of a vehicle to promote real choice for prospective tenants by providing desirable residential alternatives for households looking for properties to choose from and more a means to stimulate demand. The third and final conclusion is that ethnic minorities renting through CBL are much more likely to end up in ethnic concentration neighbourhoods than any other group. This is clear evidence of a sorting process in social housing, and one that could lead to higher levels of segregation. This outcome is in stark contrast to Pawson and Watkins (2007) and fits with the theoretical and empirical literature of housing and neighbourhood choice (see Schelling, 1971; Clark, 1991).

Our overall conclusion is that allocation mechanism for social housing will always lead to sorting simply because they act as bureaucratic gate keepers to a restricted resource. However, that there are sorting differences amongst ethnic minority and White households even when other socio-economic factors are taken into account is potentially worrying if the sorting mechanisms are leading to and reproducing spatial disadvantage. One aspect of segregation which this chapter has deliberately not commented on or analysed is how the level of segregation in neighbourhoods has changed after the introduction of CBL. To do so would require information about the outflow and well as the inflow of individuals. Nevertheless, the fact that ethnic minorities using CBL are not only the most likely to end up in ethnic concentration neighbourhoods, but also in deprived neighbourhoods suggests that the selective sorting is not only a result of choice and self-segregation, but also a result of a lack of real choice. Part of this lack of real choice seems to be structural: CBL has, to date, been most commonly offered in the most deprived neighbourhoods and the most difficult to let stock.

\section{References:}

Bailey, N., \& Livingston, M. (2008) Selective migration and area deprivation: evidence from 2001 census migration data for England and Scotland, Urban Studies, 45, 943-961.

Bolt, G., van Kempen, R., \& Van Ham, M. (2008). Minority ethnic groups in the Dutch housing market: Spatial segregation, relocation dynamics and housing policy. Urban Studies, 45, 1359-1384.

Bowes, A., Dar, N., \& Sim, D. (1997). Tenure preference and housing strategy: An exploration of Pakistani experiences. Housing Studies, 12, 63-84. 
Bråmå , A. 2006, 'White flight'? The production and reproduction of immigrant concentration areas in Swedish cities, 1990 - 2000. Urban Studies, 43, 1127 - 1146

Bråmå , A, 2007, Etnisk diskriminering pÔ bostadsmarknaden. En forskningsoversikt', IBF WP 54, Institute for Housing and Urban Research, Gavle

Bråmå , A., \& Andersson R., 2005, Who leaves Sweden's large housing estates? In Restructuring Large Housing Estates in Europe Eds R van Kempen, K Dekker, S Hall, I Tosics (Policy Press, Bristol) 169 - 192

Bråmå , A., \& Andersson R., 2010, Who leaves rental housing? Examining possible explanations for ethnic housing segmentation in Uppsala, Sweden Journal of Housing and the Built Environment

Brown, T., \& King, P. (2005). The power to choose: Effective choice and housing policy. European Journal of Housing Policy, 5, 59-75.

Brown, T., \& Yates, N. (2005). Allocations and lettings-Taking customer choice forward in England? European Journal of Housing Policy, 5, 343-357.

Burrows, R. (1999). Residential mobility and residualisation. Journal of Social Policy, 28, $27-52$.

Cabinet Office. (2003). Ethnic minorities and the labour market: Interim analytical report. London: Cabinet Office.

Champion, T. (1996). Internal migration and ethnicity in Britain. In P. Ratcliffe (Ed.), Social geography and ethnicity in Britain: Geographical spread, spatial concentration and internal migration (Ethnicity in the 1991 Census, Vol. 3, pp. 135-173). London: HMSO.

Clapham, D., \& Kintrea, K. (1984). Allocation systems and housing choice. Urban Studies, 21, 261-269.

Clark, W. (1991). Residential preferences and neighbourhood racial segregation: A test of the Schelling segregation model. Demography, 28, 1-19.

Clark, W. (1992). Residential preferences and residential choices in a multiethnic context. Demography, 29(3), 451-466.

Clark, W. A. V (1996) Households and housing: Choice and outcomes in the housing market

Clark, W. A. V, Ledwith V, 2006, Mobility, housing stress and neighbourhood contexts: evidence from Los Angeles Environment and Planning A, 38, 1077 - 1093

CLG. (2006). Monitoring the longer term impact of choice based lettings. London: Department for Communities and Local Government.

Commission for Racial Equality. (1990). Racial discrimination in an Oldham Estate Agency. Report of formal investigation into Normal Lester and Co. London: CRE.

Commission for Racial Equality. 2004 Race and council housing in Hackney: A general investigation. London: CRE.

Coombes, M. and Raybould, S. 2004 Finding work in 2001: urban-rural contrasts across England in employment rates and local job availability, Area, 36, pp. 202-222.

Crowder, K. 2000 The racial context of white mobility: an individual-level assessment the white flight hypothesis, Social Science Research, 29, pp. 223-257.

DETR. 2000. Quality and choice: A decent home for all: The housing green paper. London: Department of the Environment, Transport and the Regions.

Dorling, D., \& Rees, P. 2003. A nation still dividing: The British census and social polarization 1971-2001. Environment and Planning A, 35, 1287-1313.

Elster, J. 1999. Strong feelings: Emotion, addiction and human behavior. Cambridge: Bradford Books, MIT press.

Emerson, M. O., Chai, K. J. \& Yancey, G. 2001 Does race matter in residential segregation? Exploring the preferences of white Americans, American Sociological Review, 66, pp. 922-935. 
Feijten, P. M. \& Ham, M. van 2009 Neighbourhood change ... reason to leave?, Urban Studies, 46, pp. 2103-2122.

Fitzpatrick, S. \& Pawson, H. 2006 Welfare safety net or tenure of choice? The dilemma facing social housing policy in England, Housing Studies, 22, pp. 163-182.

Fossett M. 2006, Including preference and social distance dynamics in multi-factor theories of segregation Journal of Mathematical Sociology, 30, 289 - 298

Galster, G. 1976 Prejudice versus Preference: What do we Really Know about Housing Market Discrimination? Journal of Regional Analysis and Policy, 6(1), 17-27.

Galster, G. 2001. On the nature of neighbourhood, Urban Studies, 38, 2111-2124.

Harris, D. R. 1999. Property values drop when blacks move in, because ...: racial and socioeconomic determinants of neighbourhood desirability, American Sociological Review, $64,461-479$.

Harris, R forthcoming, "Sleepwalking towards Johannesburg"? Local measures of ethnic segregation between London's secondary schools, 2003 - 2008/9.

Henderson, J. and Karn, V. 1984. Race, class and the allocation of public housing in Britain, Urban Studies, 21, 115-128.

Hickman, P. and Robinson, D. 2006. Transforming social housing: taking stock of new complexities, Housing Studies, 21, 157-170.

Home Office. 2001. Building cohesive communities: A report of the ministerial group on public order and community cohesion. London: Home Office.

Iaonnides, Y. M., \& Zabel, J. E. 2003. Neighbourhood effects and housing demand. Journal of Applied Econometrics, 18, 563-584.

Ihlanfeldt, K. R., \& Scafidi, B. 2002. Black self-segregation as a cause of housing segregation: Evidence from the multi-city study of urban inequality. Journal of Urban Economics, 51, 366-390.

Independent Review Team. 2001. Community cohesion. A report of the independent review team. London: Chaired by Ted Cantle, Home Office.

Johnston, R. 2006. School and residential ethnic segregation: An analysis of variations across England's local education authorities. Regional Studies, 40, 973-990.

Johnston, R., Forrest, J., \& Poulsen, M. 2002. Are there ethnic enclaves/ghettos in English cities? Urban Studies, 39, 591-618.

Johnston, R. forthcoming Segregation matters; measurement matters

Kullberg, J. 1997. From waiting lists to adverts: The allocation of social rented dwellings in the Netherlands. Housing Studies, 12, 393-403.

Kullberg, J. 2002. Consumer's responses to choice based letting mechanisms. Housing Studies, 17, 549-579.

Malpass, P., \& Murie, A. 1994. Housing policy and practice (4th ed.). London: MacMillan Press

Manley, DJ \& van Ham, M. 2011. Choice-based Letting, Ethnicity and Segregation in England, Urban Studies, 48, 3125-3143.

Marsh, A., Cowen, D., Cameron, A., Jones, M., Kiddle, C \& Whitehead, C. 2004. Piloting choice based lettings: an evaluation. Office of the Deputy Prime Minister, London.

Mullins, D. and Pawson, H. (2005) 'The Land that Time Forgot': reforming access to social housing in England, Policy \& Politics, 33, 135-148.

Pawson, H., \& Kintrea, K. (2002). Part of the problem or part of the solution? Social housing allocation policies and social exclusion in Britain. Journal of Social Policy, 31, 643-667.

Pawson, H., \& Watkins, D. (2007). Quasi-marketising access to social housing in Britain: Assessing the distributional impacts. Journal of Housing and the Built Environment, 22, $149-175$. 
Pawson, H., Donohoe, A., Jones, C., Watkins, D., Fancy, C., Netto, G., Clegg, S. \& Thomas, A. 2006. Monitoring the Longer-term Impact of Choice-based Lettings; London: Dept for Communities \& Local Government.

Peach, C. 1996. Does Britain have ghettos. Transactions of the Institute of British Geographers, 21, 216-235.

Peach, C. 1998 South Asian and Caribbean Ethnic Minority Housing Choice in Britain, Urban Studies.

Robinson, D. 2007. Living parallel lives? Housing, residential segregation and community cohesion in England. In H. Beider (Ed.), Neighbourhood renewal and housing matters (pp. 163-185). Oxford: Blackwell.

Sarre, P., Phillips, D. and Skellington, R. (1989) Ethnic Minority Housing: Explanations and Policies. Aldershot: Avebury.

Schelling, T. C. 1969. Models of segregation. The American Economic Review, 59, 488-493.

Schelling, T. C. 1971. Dynamic models of segregation. Journal of Mathematical Sociology, $1,143-186$.

SEH. 2007. Housing in England 2005/06: A report principally from the 2005/06 survey of English Housing. London: Department for Communities and Local Government.

Simpson, L. 2004. Statistics of racial segregation: Measures, evidence and policy. Urban Studies, 41, 661-681.

Simpson, A. 1981 Stacking the decks. Nottingham Community Relations Council, Nottingham.

Simpson, L. 2004 Statistics of racial segregation: measures, evidence and policy, Urban Studies, 41, pp. 661-681.

Somerville, P. 2001 Allocating housing or letting people choose?, in: D. Cowan and A. Marsh (Eds) Two Steps Forward: Housing Policy into the New Millennium, pp. 113132. Bristol: Policy Press.

South S J, Crowder K D, 1997, Escaping distressed neighbourhoods: individual, community and metropolitan influences. American Journal of Sociology $1021040-1084$

South, S. J. \& Crowder, K. D. 1998. Avenues and barriers to residential mobility among single mothers, Journal of Marriage and the Family, 60, 866-877.

Taub, R. P., Taylor, G. D. \& Dunham, J. D. 1984 Paths of Neighbourhood Change. Chicago, IL: University of Chicago Press.

Turner M, A., Ross S, L., Galster G, C., Yinger J, 2002. Discrimination in Metropolitan Housing Markets: National Results from Phase I HDS 2000 (The Urban Institute, Washington, DC)

van Ham, M. \& Clark, W. A. V. 2009. Neighbourhood mobility in context: household moves and changing neighbourhoods in the Netherlands, Environment and Planning A, 41, 1442-1459.

van Ham, M. and Feijten, P. 2008. Who wants to leave the neighbourhood? The effect of being different from the neighbourhood population on wishes to move, Environment and Planning A, 40, 1151-1170.

van Ham, M. and Manley, D. 2009. Social housing allocation, choice and neighbourhood ethnic mix in England, Journal of Housing and the Built Environment, 24, 407-422.

van Ham M. 2012. Housing Behaviour. In D. Clapham, W.A.V. Clark and K. Gibb (eds) Handbook of Housing Studies. Chapter, 3. Sage: London. 